\title{
Analysis of the Characteristics of the Haze in Recent 3 Decades in Chengdu
}

\author{
Na Xieㄹ, Peng Yao², Dongfu Xu1 ${ }^{1}$, Dongfang Zhang ${ }^{1}$ \\ ${ }^{1}$ Chengdu Provincial Meteorological Bureau, Chengdu, China \\ ${ }^{2}$ Chengdu Provincial Dayi County Meteorological Bureau, Chengdu, China \\ Email: xiena991980@163.com
}

How to cite this paper: Xie, N., Yao, P. $\mathrm{Xu}$, D.F. and Zhang, D.F. (2017) Analysis of the Characteristics of the Haze in Recent 3 Decades in Chengdu. Journal of Geoscience and Environment Protection, 5, 196209.

https://doi.org/10.4236/gep.2017.57015

Received: March 31, 2017

Accepted: July 21, 2017

Published: July 24, 2017

Copyright (C) 2017 by authors and Scientific Research Publishing Inc. This work is licensed under the Creative Commons Attribution International License (CC BY 4.0).

http://creativecommons.org/licenses/by/4.0/

\section{Open Access}

\begin{abstract}
It is valuable to study the characteristics of haze change to make good efforts to control air pollution. The haze days in recent 3 decades in Chengdu were counted by 14 hour method, coming to the following results: 1) the number of haze days in Chengdu has decreased and then increased in the recent $3 \mathrm{dec}$ ades; 2) the number of haze days in autumn and winter accounts for $70 \%$ of the year-round number. The spatial distributed characteristic of haze in Chengdu is that it is rare in northwestern Chengdu and common in southwestern Chengdu. Compared with Dujiangyan, the environmental background field of Chengdu, haze trends to become more serious in Shuangliu; 3) according to the comparative analysis on the AQI of 2013 and number of haze days, the methodologically-counted haze days correspond to moderate pollution weather, and this is well reflected in autumn and winter. It is susceptible to the rainfall system in summer; 4) the primary pollutant in Chengdu is PM2.5, followed by PM10. The climatic background is inimical to pollutant diffusion. Besides, the expansion of urban area and the change of people's lifestyle are significant causes of the increase in the number of pollution days.
\end{abstract}

\section{Keywords}

Chengdu, Haze, Spatial-Temporal Analysis

\section{Introduction}

With their environmental consciousness being raised, people have been increasingly concerned with the effect and harm of haze. At present, the four severe haze-polluted areas in China are Huang-Huai-Hai Region, Sichuan Basin, Pearl River Delta and Yangtze River delta [1]. The domestic studies on haze have come into being gradually since 2000 , most of which are systematic ones focusing on the Pearl River Delta, but there are also studies related to the Yangtze 
River delta and Beijing-Tianjin-Hebei Region [1] [2]. For instance, Wu Dui summarized the climatic features of the haze in Guangzhou and the causes of haze weather during the Asian Games [3]. Zhao Pusheng analyzed the features of the haze weather in the Beijing-Tianjin-Hebei region [4]. But there are few studies on the characteristics of the haze in Sichuan Basin, particularly Chengdu.

Chengdu is the most important city in Western China, where economy develops rapidly; infrastructure including urban roads and traffic facilities is constructed quickly; vehicle population grows rapidly, and pollutant emission rises to some extents. So, the air quality problem is becoming more and more serious in Chengdu, drawing attention from the Chengdu Municipal Government and citizens. Therefore, we made a study on the spatial and temporal distribution characteristics of haze in Chengdu in the recent 3 decades, and conducted a tentative analysis on the influencing factors of haze. This has positive significance to the forecast and prevention of the haze in Chengdu, as well as the evaluation of its effect.

\section{The Definition of Fog and Haze and the Comparison of Meteorological Statistical Methods}

\subsection{The Definition of Fog and Haze}

Both fog and haze are weather phenomena that obscure vision, and the major difference between them lies in humidity. If the horizontal visibility of target objects is reduced to below $1000 \mathrm{~m}$, the moisture condensate suspending in surface air is called fog; and the condensate is called light fog if the horizontal visibility of target objects is between 1000 and $10,000 \mathrm{~m}$; the obstruction to vision caused by the aerosol system consisting of such non-hydrometeors is called haze if the horizontal visibility is less than $10,000 \mathrm{~m}$. Haze is $1-3 \mathrm{~km}$ thick, its daily variation is not obvious, and there isn't apparent boundary between it and clear sky [5]. Components of haze include $\mathrm{SO}_{2}$ and $\mathrm{NO}_{2}$ in Chengdu. According to 2015 Chengdu Environmental Quality Bulletin released by Chengdu City Peoples Government, in 2015 , emissions of $\mathrm{SO}_{2}$ were $4.4 \times 10^{4} \mathrm{t}$, while emissions of $\mathrm{NO}_{2}$ were $8.1 \times 10^{4} \mathrm{t}$.

Fog and haze can be converted into each other. When relative humidity $(\mathrm{RH})$ exceeds $100 \%$, such as in a radiative cooling process, the liquid water separated out from haze particles becomes fog drops, but when $\mathrm{RH}$ decreases, haze particles form haze suspending in the atmosphere after fog drop dehydration.

\subsection{Screening of Haze Statistics Methods}

Haze must be defined to study its variation characteristics. There is some controversy over this standard in statistical processes, and a statistical standard consisting of single technique, daily averaging method and 14 hour method has been formed in practice in recent years [2] [3].

According to single technique, if haze occurs at an observation interval during 1 day, the day will be considered to be 1 haze day. Daily averaging method defines average daily meteorological optical range (MOR) as less than $10 \mathrm{~km}$ and 
average daily $\mathrm{RH}$ as less than $90 \%$, to define a day in which water, snow drift, snowstorm, blowing sand, dust storm or smoke screen reduces MOR as a haze day.

The data with a MOR of less than $10 \mathrm{~km}$ analyzed by 14 hour method must meet the following 3 conditions simultaneously: 14:00; code 01 (dew), 02 (frost), 03 (freeze), 04 (smoke screen), 05 (haze), 10 (light fog), and 42 (fog); a day in which $\mathrm{RH}$ is less than $90 \%$ is recorded as a haze day. $\mathrm{RH} 90 \%$ is taken as a line of demarcation between haze and light fog (fog), so when RH exceeds $90 \%$, light fog (fog) occurs, and when RH is less than $90 \%$, haze occurs. In this way, not only can light fog (fog) be separated from haze, but haze can be separated from light fog (fog). Meanwhile, weather phenomenon codes can be used to identify precipitation, snowdrift, snowstorm, dust blowing, dust storm, aerial dust, smoke screen and other relevant weather events. This method is extensively used in the world to investigate the long-term variation trend of MOR [4].

Chengdu is located at the bottom of Sichuan Basin, which features large still wind frequency and high humidity. In autumn and winter, temperature inversion is apt to occur in Chengdu, and fog or light fog is very easy to occur in mornings, so it is improper to define the haze days in Chengdu by daily averaging method or single technique. For Chengdu, what matters most is the condition of haze in daylight, so 14 hour method is a representative method for this region.

\section{Analysis of the Variation Characteristics of Haze in Recent 3 Decades in Chengdu}

\subsection{Annual Variation Trend}

Three typical stations were adopted in this paper for analysis of the characteristics of the haze in Chengdu. Shuangliu is located in Southwestern Chengdu, 12 $\mathrm{km}$ away from the downtown area straightly. There is no clear boundary between it and the downtown area due to the high urbanization speed. Dujiangyan is located in northwestern Chengdu, where urbanization is slower than other districts and counties. The environmental protection bureau has taken Dujiangyan as the environmental background field. Also, Dujiangyan has been taken as the climatic and environmental background field in this paper. Wenjiang is located in northern Chengdu, which is a national base station.

Taking Wenjiang for example, the variation trend of haze in the recent $3 \mathrm{dec}-$ ades was calculated by 14 hour method. The annual average total number of haze days was 47.1: The early 1980s and 1990s saw many haze days, during which the annual average total number was basically larger than 50 , and the number reached its peak value in 1986, which was 65 . The period from the early 1990s to 2010 saw fewer haze days, during which the annual average total number was basically about 40 , and the number reached its peak value in 1999, which was 32 . The number of haze days began to increase in 2010, and remained above 50 from 2008 to 2012.

The 30-year trend of haze in Shuangliu is basically the same as that in Du- 
jiangyan, since haze first decreased and then increased in quantity in both regions. Comparatively speaking, despite a small variation in Dujiangyan, the variation trend was basically the same as that in other stations. As can be seen from the difference in number of haze days between Dujiangyan and Shuangliu, the number of haze days increased from the 1980s till now in both stations. Especially, the difference in number of haze days reached 35 per year after 2006, 10 larger than in the middle 1980s. Apart from the general climatic background, the local climate change caused by the quick increase of city size in Shuangliu, etc. is the major factor leading to the difference in number of haze days between Shuangliu and Dujiangyan.

As shown in Figure 1, a change took place in the number of haze days around 1994 over the 3 decades. There were a large number of haze days in Chengdu before 1994, and the total number decreased after 1994, but this did not mean that the air quality got better in Chengdu. Since heat island and arid island effects began to become obvious in Chengdu in the early 1990s, (Hao Liping also pointed in the climatic characteristics of Chengdu that the climate in Chengdu hit a turning point in 1993) fog scarcely occurred, while haze often occurred.

As can be seen in Figure 2, since the 1980s, the humidity in Chengdu has shown a downtrend, particularly since 2000 , the extent of decrease has been very obvious. The average RH in Chengdu was greater than $83 \%$ before 1993, and
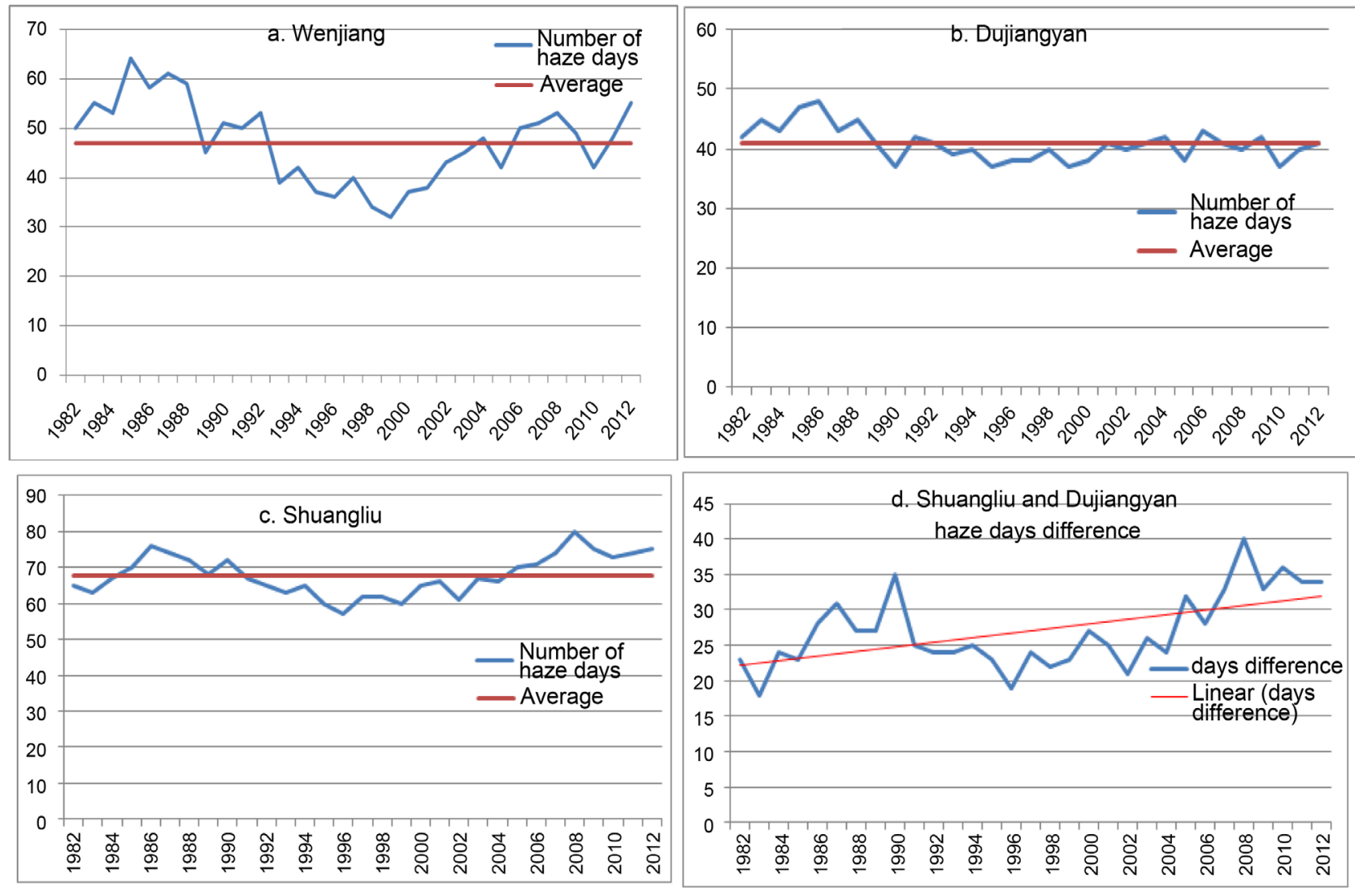

Figure 1. Haze days change trend on behalf of the station nearly 30 years in Chengdu (a) Wenjiang, (b) Dujiangyan, (c) Shuangliu, (d) Shuangliu and Dujiangyan days difference). 


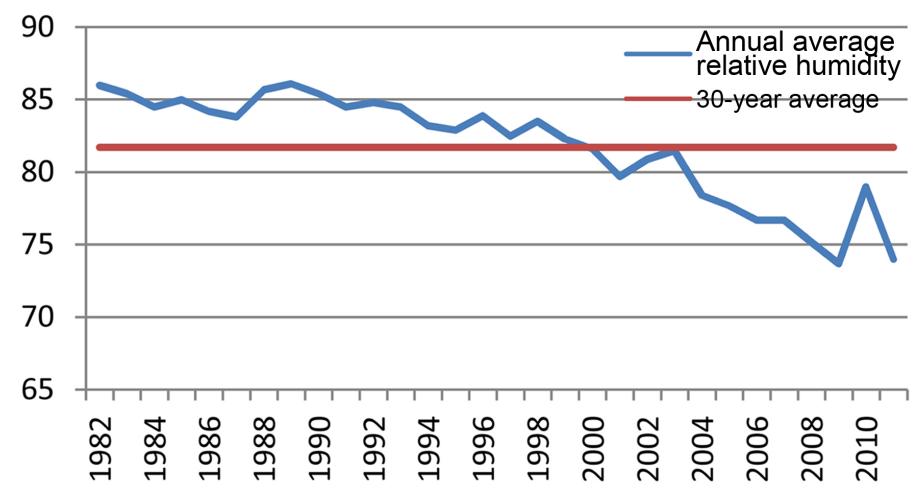

Figure 2. Trend of Relative Humidity in Wenjiang Station in Recent 30 Years.

above $80 \%$ from 1993 to 2003 . The average $\mathrm{RH}$ just remained around $75 \%$ from 2004 to 2011.

According to the analysis, Chengdu was in a haze-prone period from the 1980 s to 1990 s, the humidity was high, and the particulate matters wrapped in water drops easily formed fog. The humidity in Chengdu was around $80 \%$ from the middle 1990s to $2004,3 \%$ lower than ten years ago. With water vapor dying away and particulate matters having increasingly weak ability to absorb moisture to form fog drops, Chengdu gradually went out of the haze-prone period. The humidity further decreased after 2004, and meanwhile urbanization sped up, so more particulate matters began to suspend in the air. Moreover, with the urban heat land effect improving, more suspended naked particulate matters entered the air, and the number of haze days increased in Chengdu. What's worse, the number of haze days increased, especially in recent 5 years, only around 3 foggy days appeared in Chengdu in autumn and winter, the number decreasing by $35 \%$ compared to the average historical number.

\subsection{Seasonal Variation Trend}

According to the analysis of Figure 3, the monthly average showed a " $U$ "shaped variation trend, namely the peak decreased to valley and then bounced. The monthly average of 3 decades shows that the number reached its peak in January, followed by December, and reached its minimum in August, which was equal to 7.8, 7.4 and 0.3 respectively. The number in January, February, November and December accounted for $70 \%$ of the annual number.

Throughout the year, winter (December-February) saw the largest number of haze days which was 20.1, accounting for $53.3 \%$ of the annual number, and summer (June-August) saw the smallest number which was 1.8, accounting for $4.9 \%$ of the annual number. The number was 10.1 in autumn (September-November), and 5.7 in spring (March-May). The number of haze days in winter and autumn accounted for $80.1 \%$ of the annual number. See Figure 4.

In pollution diffusion, meteorological conditions play a decisive role. In autumn and winter, calm weather prevails in Chengdu, and since the temperature difference between morning and evening is not big, temperature inversion often 
1982-2011 years haze days average change curve

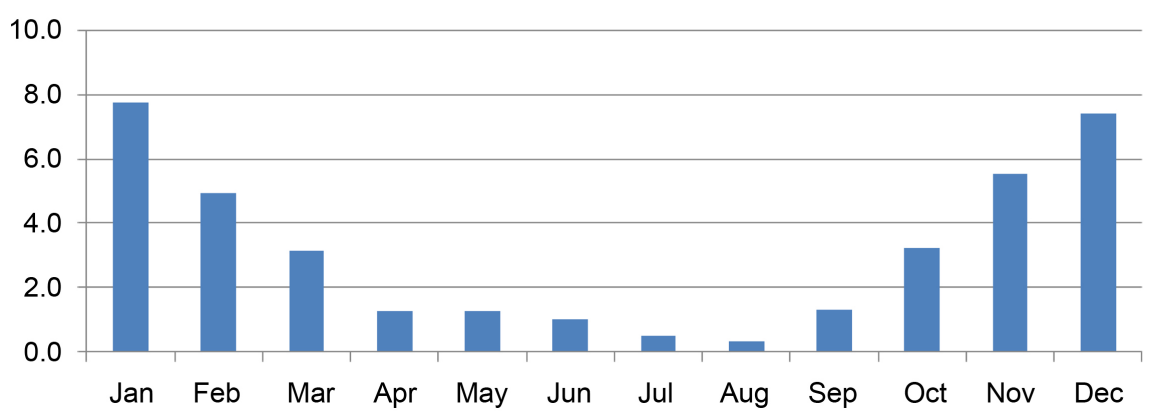

Figure 3. Salween stand nearly 30 years fog on the average days change trend.

The fog haze days in 1982-2011 season average

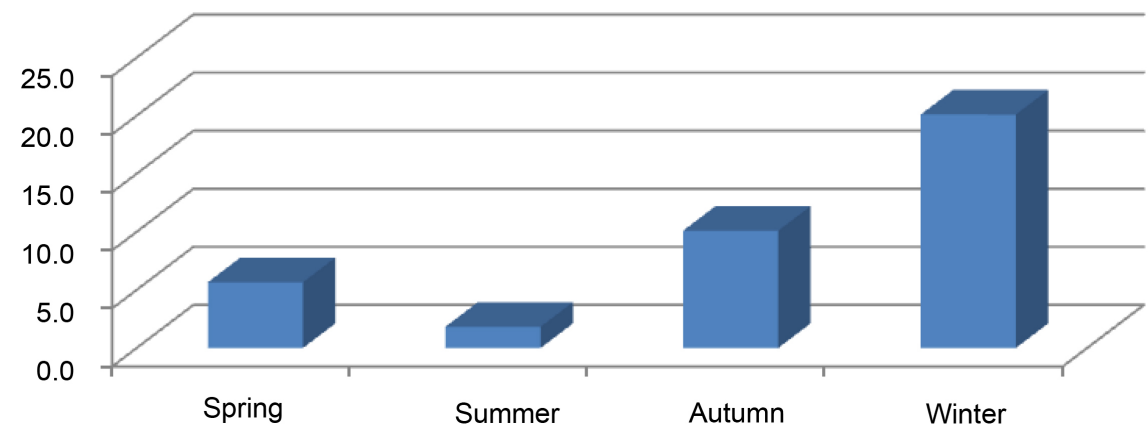

Figure 4. Salween stand nearly 30 years fog four seasons change trend.

occurs. The surface wind speed is low, the number of rain days is small, and the basic rainfall is around $1 \mathrm{~mm}$. All this is inimical to pollutant diffusion, so, under normal circumstances, small rainfall has a great precipitating effect on PM10, while little on PM2.5, and it may even lead to an increase in the content of PM2.5 in the air. For this phenomenon, a fair explanation is that raindrops increase in number in the descending process of micro-particles wrapped in raindrops high in the sky, and the small particles wrapped are released to form naked PM2.5 at low altitudes to increase the content of PM2.5. So, in the whole winter, the moderate or severe pollution days in Chengdu account for over $70 \%$.

In summer, there is the least likelihood that haze falls in Chengdu, because the coarse particles in the atmosphere are mainly removed by wet deposition. In summer, adequate rainfall scours away the suspended coarse particles including dust in the air and inhabits the formation of haze [5]. In addition, air convection flourishes in summer, and diffuses the pollutants (in particular, fine particulate pollutants) in the surface layer, so haze rarely occurs [6].

\subsection{Spatial Distribution}

As can be seen in Figure 5, the spatial distribution characteristic of haze in Chengdu is that there is least haze in northwestern Chengdu, represented by Dujiangyan, most in southern Chengdu, represented by Shuangliu, and moderate in eastern Chengdu such as Xindu and Jintang. This is because western Chengdu is a mountain area, and the near-surface dominant wind in Chengdu is 


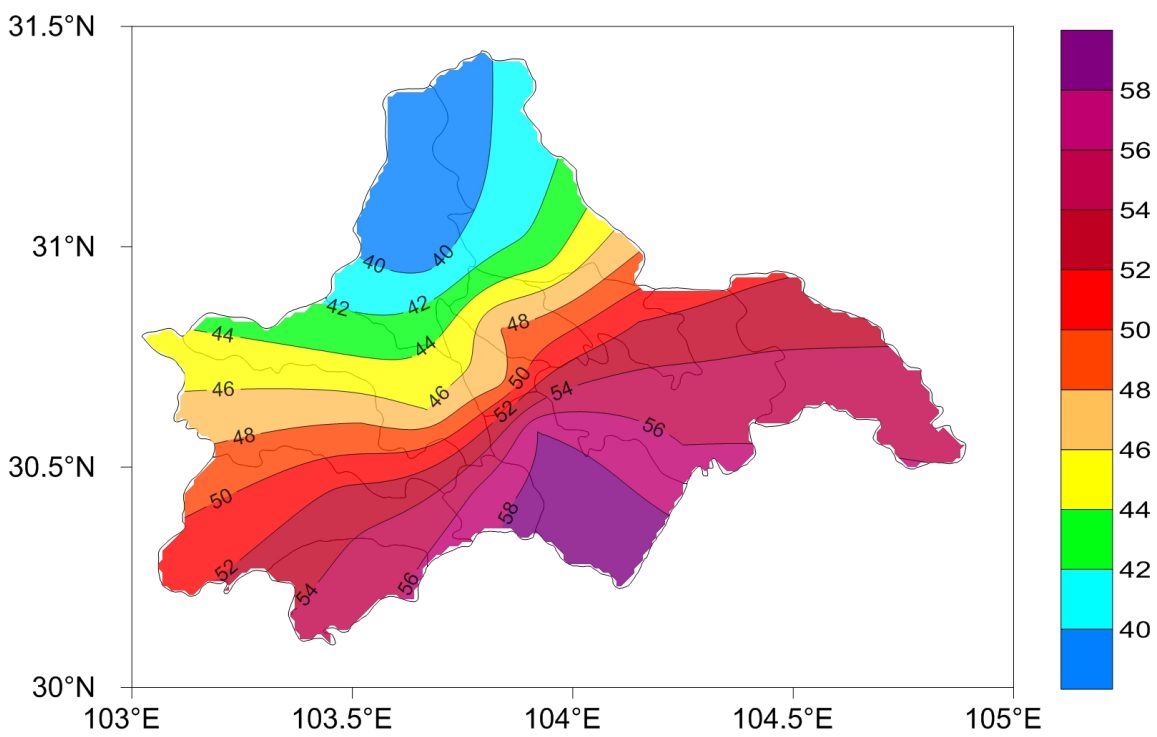

Figure 5. Chengdu area distribution of fog.

1-2-grade northeasterly wind, so under the topographical action, moisture converges in western, especially southwestern Chengdu. Relatively speaking, the annual average $\mathrm{RH}$ is higher in western Chengdu than eastern Chengdu. For Dujiangyan, which is located in northwestern Chengdu, its altitude is around $200 \mathrm{~m}$ higher than Chengdu urban areas', and that Dujiangyan Station is located in a tuyere area where the wind speed is greater than that in the urban area, so the number of haze days is small there.

Compared with the haze-prone year (1988) and low-frequency year (2007), there is basically no difference in haze distribution frequency between the districts, cities and counties of Chengdu. This is because haze forms based on local specific terrain factors under the general weather background. Of course, its formation is also related to the pollutant emission in the locality.

In Chengdu, Dujiangyan and Pujiang are the districts or counties farthest from Chengdu, so relatively speaking, the urbanization degree is comparatively low there, thus they can be regarded as background fields of spatial haze distribution. According to the comparison of haze day number between 2007 and 2008, haze was aggravated in Shuangliu, and compared with the number in Dujiangyan in 1998, the number of haze days in both Shuangliu and Dujiangyan increased obviously.

\section{Haze Composition Characteristics}

\subsection{Corresponding Analysis of Haze Days and Pollution Weather}

Since there is no big monitoring station but just automatic weather stations in Chengdu urban area, haze can only be judged by other alternative methods. Among the 13 weather stations in Chengdu City, Longquan and Shuangliu are farthest from Chengdu urban area straightly. Longquan Observation Station is $27.15 \mathrm{~km}$ away from People's Park Station, and Shuangliu Observation Station is $23.82 \mathrm{~km}$ away from People's Park Station. According to the 14 hour method 
mentioned above, if there is haze in either Shuangliu or Longquan, it is thought that there is haze in Chengdu urban area, too (see Table 1).

So, there were 60 haze days in Chengdu urban area in 2013. See Table 2 for the monthly distribution. As can be seen, there was the largest number of haze days in January, which achieved 14, while there was no haze in August.

As shown in Figure 6, in winter (December, January and February), haze days account for over half of the total days, and moderate pollution days account for $60 \%$ of the total days. Several heavy pollution days are obviously reflected in MOR and other relevant meteorological elements, suggesting that 14 hour method can identify not only haze weather, but also heavy pollution weather. But there are two problems needing attention: first, diffusion condition is better in midsummer, and it is a low probability that moderate or severe pollution weather appears. The haze occurring at this time usually has something to do with heavy rainfall. In July-August, there is usually thermal low pressure on the ground in Chengdu, so when weak cold air comes from north, the frontal zone will be enhanced in the northern basin, and wind speed will increase slightly on the ground in Chengdu in the afternoon or at nightfall. As a result, airflow will ascend in the whole layer, to cause dust from land surface to lower the MOR. But the corresponding pollutant concentration is not necessarily high. This needs to be excluded in practical operational application. Second, haze statistics respond to pollutant concentration accumulation dully. That is, MOR cannot be reflected unless one or two days later after the occurrence of moderate pollution, so generally speaking, the statistical number of haze days is smaller than the actual

Table 1. In 2013 there was a haze of Longquan and Shuangliu 14 days.

\begin{tabular}{cc}
\hline Station & 14 o'clock \\
\hline Longquan & 40 \\
Shuangliu & 55 \\
\hline
\end{tabular}

Table 2. The number of days of haze in 14 months in Chengdu City in 2013.

\begin{tabular}{ccccccccccccc}
\hline Month & 1 & 2 & 3 & 4 & 5 & 6 & 7 & 8 & 9 & 10 & 11 & 12 \\
\hline Day & 14 & 9 & 5 & 2 & 5 & 3 & 2 & 0 & 3 & 5 & 4 & 8 \\
\hline
\end{tabular}

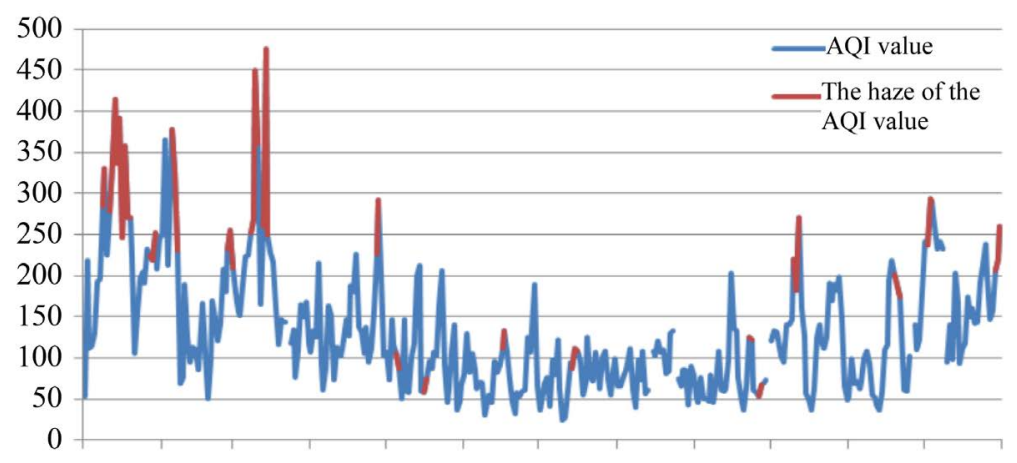

Jan 1 Feb 1 Mar 1 Apr 1 May 1 Jun 1 Jul 1 Aug 1 Sep 1 Oct1 Nov 1 Dec 1

Figure 6. The AQI value corresponding to the haze day in 2013. 
number of pollution days.

As shown in Figure 7, the observation of PM2.5 began in 2013. As can be seen, the primary pollutant in Chengdu urban area is PM2.5, which accounts for $87 \%$ of the annual day number, and PM10 accounts for $11 \%$, which accounts for over $92 \%$ given mild, moderate or severe pollution, and for $97 \%$ given moderate or severe pollution. On fine days in summer, PM10 and O3 can become principal pollutants, the corresponding AQI does not exceed 80 generally, and the primary pollutant is basically PM2.5 in autumn and winter.

This is because the large number of pollution days, as well as the fact that the primary pollutant is PM.5, is a common result of natural and anthropogenic causes. Chengdu is located in the central basin, which features high humidity, still wind frequency, highly possible temperature inversion, and insignificant temperature difference between morning and evening. The general climatic background decides a high possibility of haze occurrence in Chengdu. In midsummer (July-August), the air quality in Chengdu is basically excellent and good. This is because there is a low probability of temperature inversion in summer, day temperature is very high, which corresponds to an upward radiant flux, the mixed-layer height is high, which may reach $1-2 \mathrm{~km}$, and upward diffusion is good. At night, temperature decreases, and radiant flux goes down,

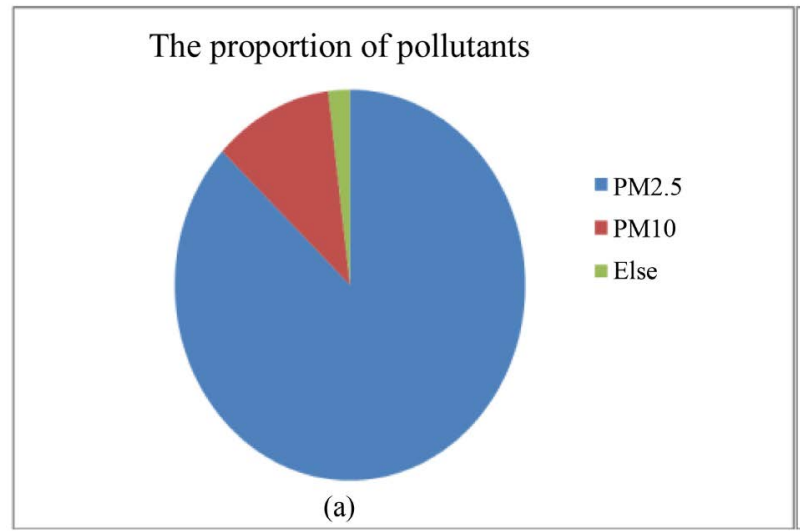

Mild pollution to the above proportion of pollutants

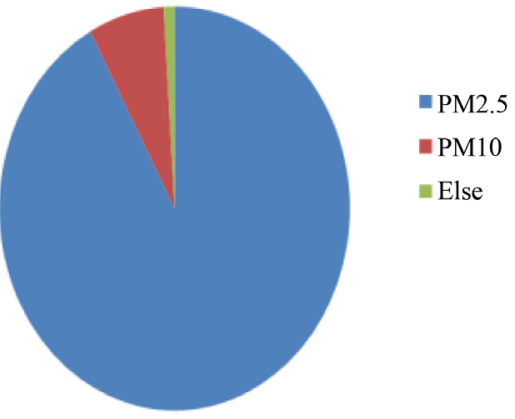

(b)

Figure 7. The proportion of pollutants in 2013 (a) the proportion of pollutants throughout the year (b) mild pollution above the proportion of pollutants). 
producing a precipitating effect on pollutants. Heavy rainfall prevails in summer, big raindrops rarely evaporate, and the pollutants wrapped in raindrops are not exposed, so PM2.5 concentration is raised. Rainfall intensity is high in summer, which drags pollutants down powerfully, so the PM2.5 in the air attenuates obviously.

Autumn and winter are pollution-prone periods in Chengdu. The weather characteristic of Chengdu in winter is that temperature inversion occurs in mornings, surface wind speed is low, there is no sunshine, humidity is high, the temperature difference between morning and evening is small, the rainfall depth is around $1 \mathrm{~mm}$, and there is no evident effect on PM2.5 abatement. Therefore, moderate or severe pollution often occurs in Chengdu in winter. What has an evident mitigative effect on the heavy pollution weather in winter is southbound cold air, and moderate or slightly weaker cold air has a very evident effect on pollutant diffusion in Chengdu.

\subsection{The Relationship between Haze Weather and Urbanization}

The seasonal variation of haze identified above is attributed to not only the intensity of cold air activities, but also the effective number of rain days, whereas the main factor is nothing but the frequency and intensity of cold air. Leaving aside meteorological factors, the increasingly large number of airborne particles caused by urbanization is also an important factor related to the formation of haze.

As can be seen from the $500 \mathrm{hpa}$ height field and departure field in the winters (December that year, as well as January and February the year ensuing) in the same decade (e.g., the 1980s, and after 2000), meteorological conditions decided the number of haze days in adjacent years.

As shown in Figure 8 and Figure 9, in the winter of 1984, there was a low pressure from Ba Lake to Bei Lake, corresponding to meions, and Urals high ridge corresponded to strong pleions, so cold air traveled southward easily. There were meions from the plateau to the basin, which helped move fluctuations eastward to affect Chengdu, and brought about available rainfall with the cold air. There were only 37 haze days in Chengdu in the winter of 1984. On the contrary in 1985, weak ridge corresponded to pleions from Ba Lake to Bei Lake, while Urals high ridge corresponded to meions. The obvious zonal performance at mid-high latitudes stopped cold air from traveling southward. There were a larger number of haze days in the winter of 1985 than 1984, and the number was 45.

According to the comparison between similar circulation patterns, such as 1993 and 2012, low trough corresponded to meions from Ba Lake to Bei Lake, while Urals high ridge obviously corresponded to pleions. The only difference is that the southern branch trough was more obvious in 2012. There were 29 haze days in the winter of 1993, and 39 in the winter of 2012. Given roughly the same climatic background, the increasing number of airborne particles was the key to the increasing number of haze days. 
1984
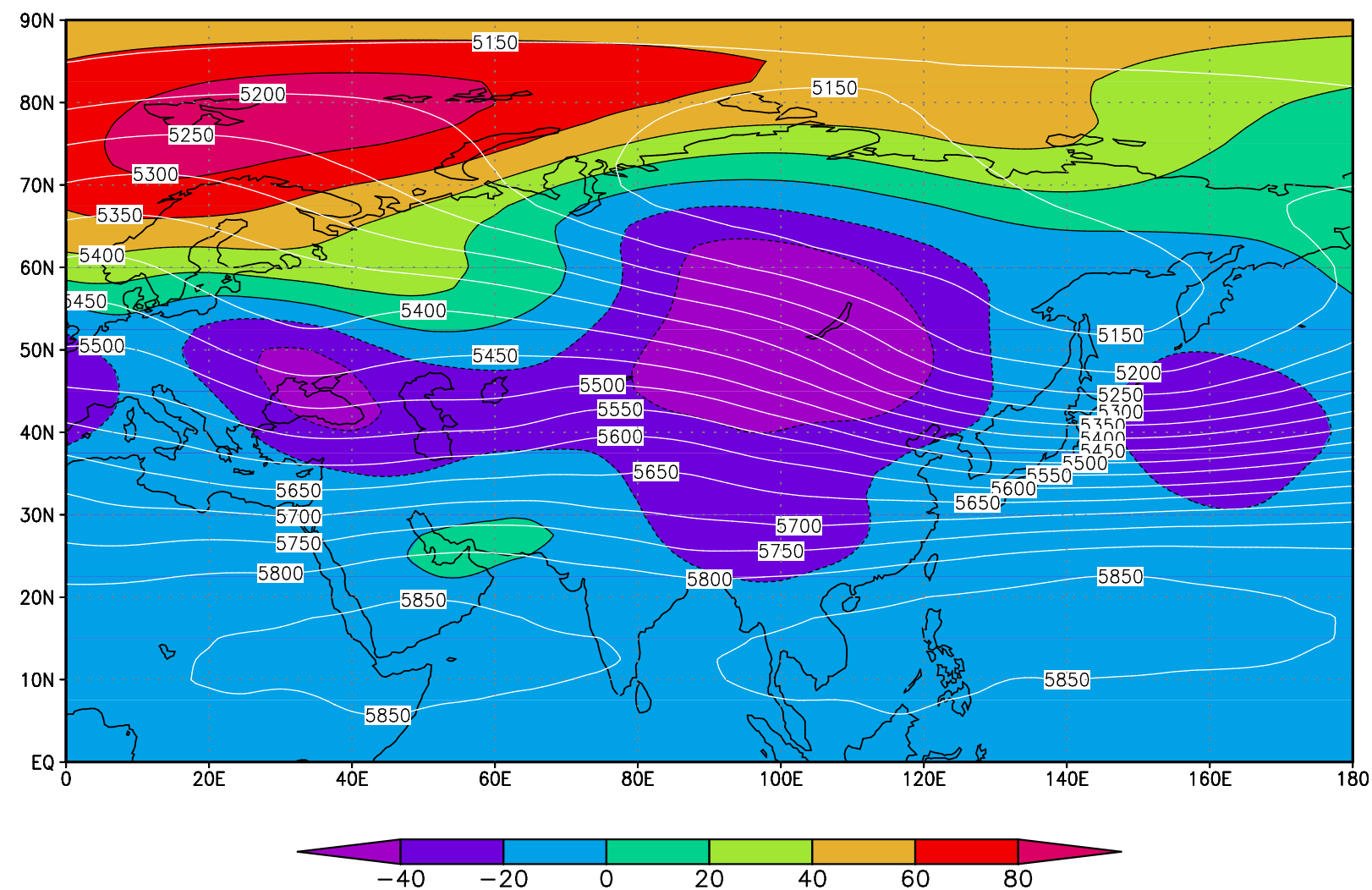

2015-01-19-11:12

\section{5}

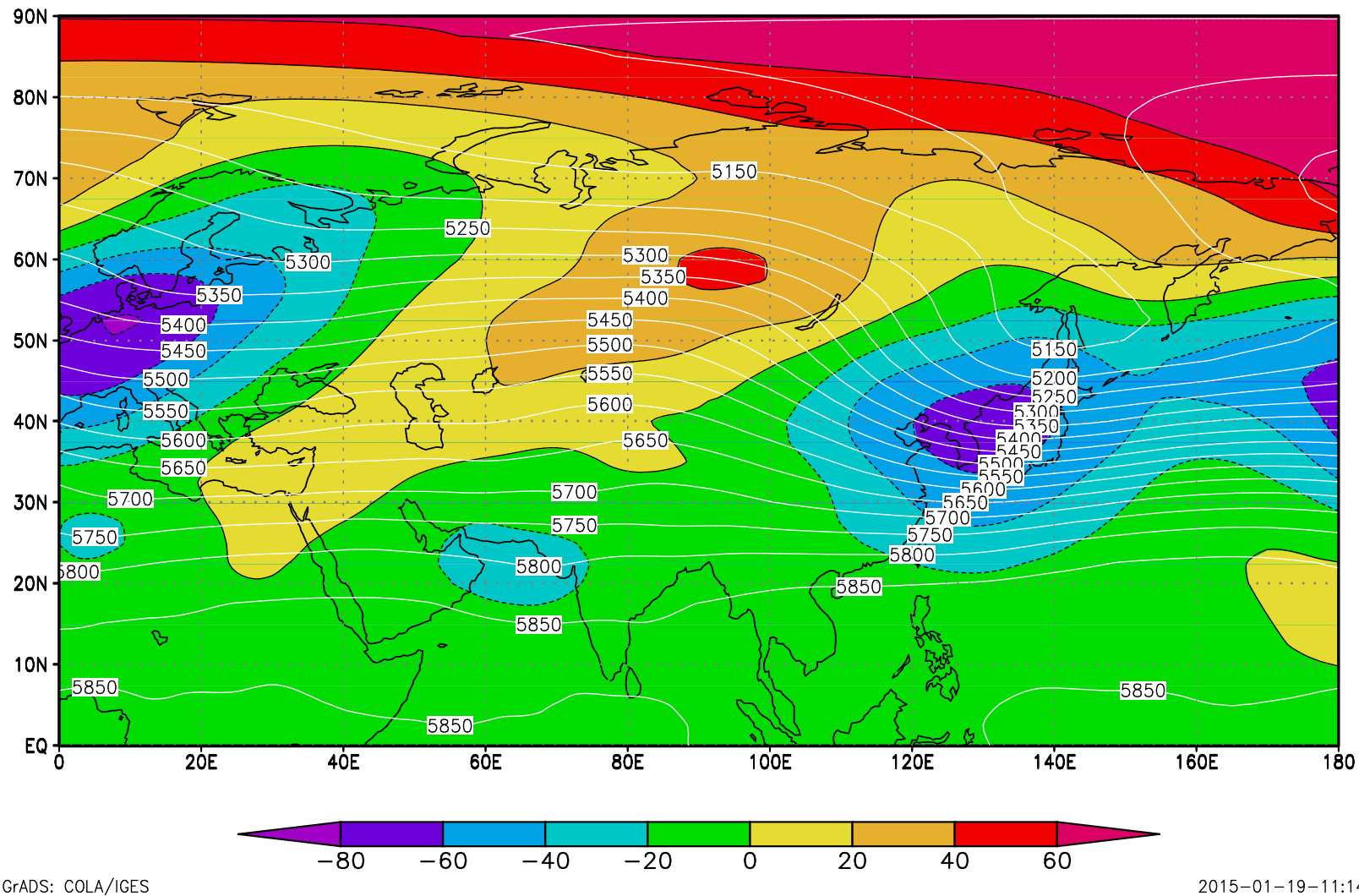

Figure 8. 1984 and 1985 winter 500 hpa height and distance from the field. 
1993

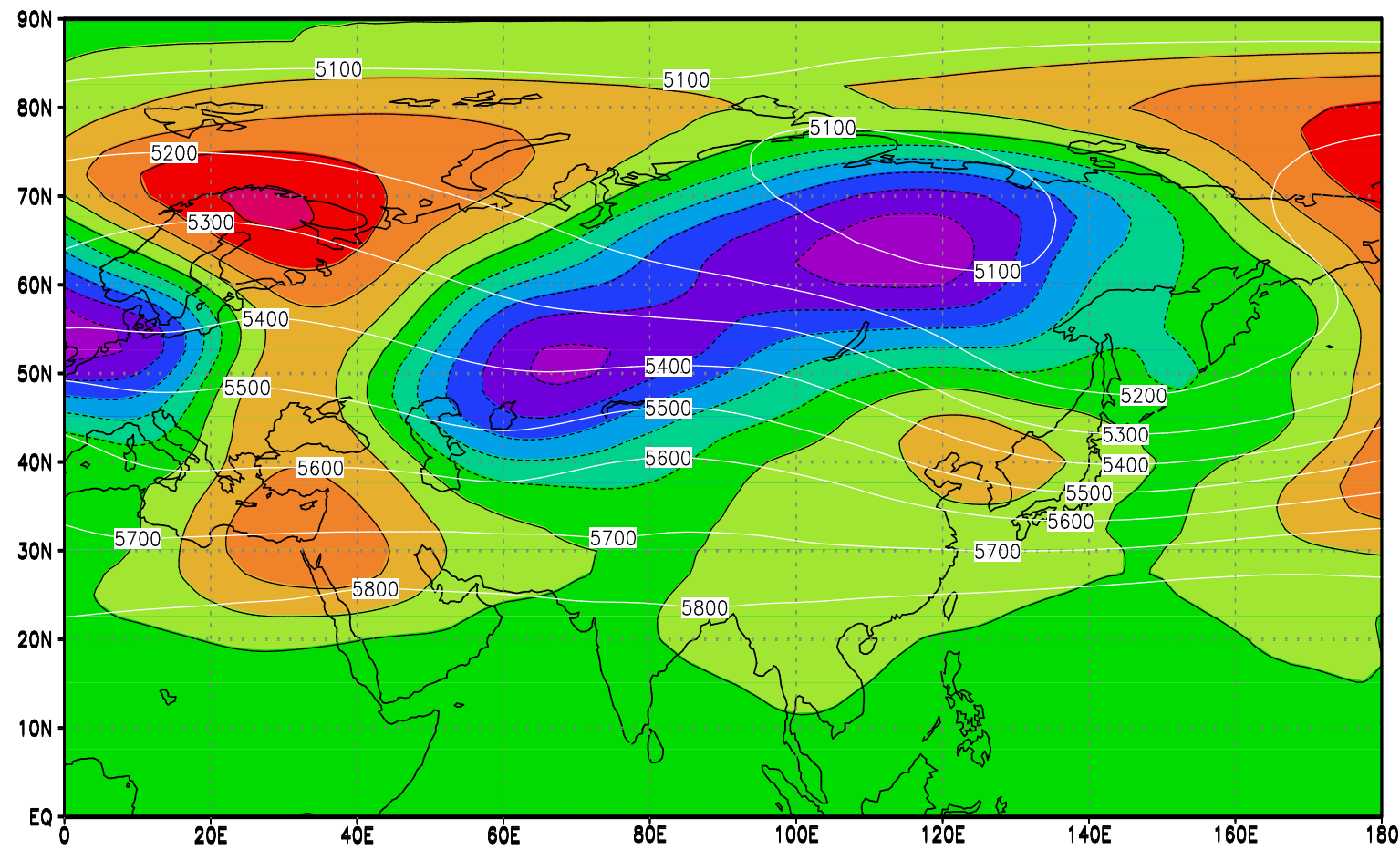

GrADS: COLA/IGES

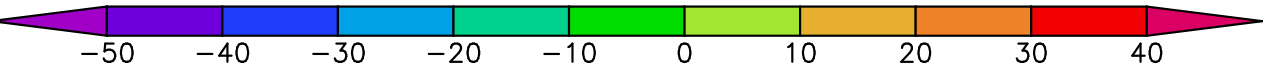

2012

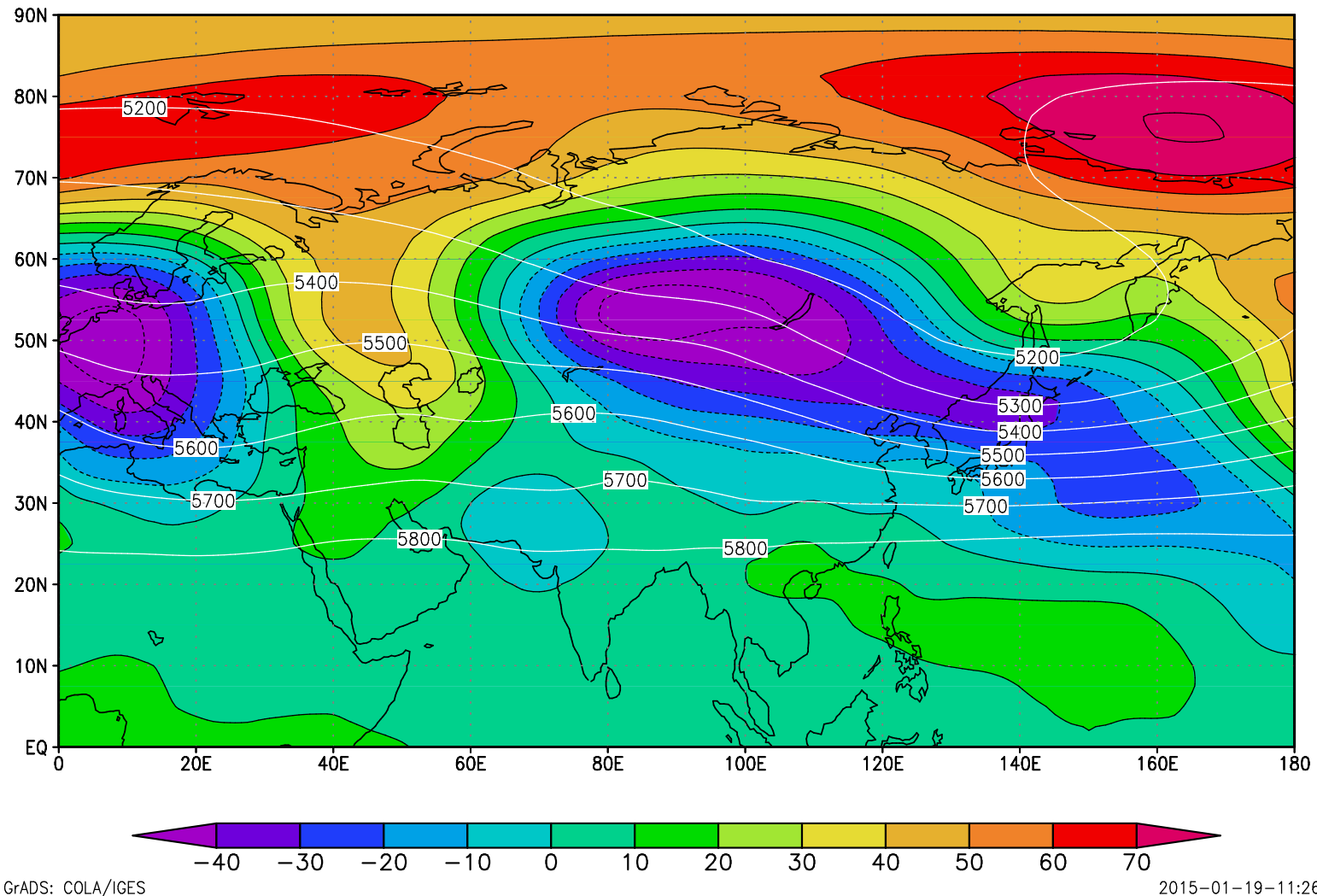

Figure 9. 1993 and 2012 winter $500 \mathrm{hpa}$ height and distance from the field. 
Many studies show that the expansion of urban area and the change of people's lifestyle have very enormous influence on haze weather [7] [8] [9] [10].

The urban area of Chengdu reached $515 \mathrm{~km}^{2}$ by 2012, almost doubled compared to 2003 when the area was $265 \mathrm{~km}^{2}$, and the permanent resident population was 14.17 million. The motor vehicle population was 3.13 million, and in this aspect, Chengdu ranked the second at home, next only to Beijing. The expansion of urban area, the growth of population and the increase of motor vehicle population led to a sharp increase in the quantity of airborne particles. This is why the number of haze days has increased constantly in recent years.

\section{Conclusions}

1) The occurrence of haze in Chengdu in recent 3 decades is divided into 3 stages: haze-prone period began in the 1980s and ended in the early 1990s; lowfrequency period began in the middle 1990s and ended in 2003; haze growth period began in 2003 and ended in 2012. Apart from the climatic background, the increasing number of particulate matters, the urban heat island effect and arid island effect are also key factors.

2) Throughout the year, the number of haze days in autumn and winter accounts for $70 \%$ of the annual number. In these two seasons, calm weather prevails in Chengdu; the temperature difference between morning and evening is not big; temperature inversion often occurs; the surface wind speed is low; there are a smaller number of rain days, and the rainfall depth is usually $1 \mathrm{~mm}$. All these are beneficial to the formation of haze.

3) The spatial distribution characteristic of haze in Chengdu is that there is less haze in northwestern Chengdu, while more in southwestern Chengdu. According to the difference in haze day number between Dujiangyan and Shuangliu in 2007 and 2008, 2007 saw aggravation of haze in Shuangliu.

4) According to the comparative analysis on the AQI of 2013 and number haze days, the meteorological statistical number of haze days corresponds to moderate pollution weather, and this is well reflected in autumn and winter. It is susceptible to the rainfall system in summer.

5) The primary pollutant in Chengdu is PM2.5, followed by PM10. The climatic background is inimical to pollutant diffusion. Moreover, the expansion of urban area and the change of people's lifestyle are also important causes for the increasing number of pollution days.

\section{Acknowledgements}

The study was funded by the Ministry of Science and Technology Fund "Southwest region fog - haze research and forecast early warning demonstration" project.

\section{References}

[1] Wu, D., Liao, B.T. and Wu, S. (2012) Analysis of Haze Weather during the 2010 Guangzhou Asian Games. Journal of Environmental Science, 32, 521-527. 
[2] Wu, D. (2006) On the Difference between Urban Haze and Fog. Meteorological, 32, 9-15.

[3] Wu, D. (2008) Haze and Fog Identification and Data Analysis and Processing. Environmental Chemistry, 27, 327-330.

[4] Zhao, P.S., Xu, X.F. and Meng, W. (2012) Characteristics of haze in Beijing - Tianjin - Hebei Region. Chinese Journal of Environmental Science, 32, 31-36.

[5] Sun, X., Yin, Y. and Sun, Y.W. (2011) Study on Aerosol and Haze Weather Sol in Shijiazhuang Area. Chinese Journal of Environmental Science, 31, 705-713.

[6] Wu, M., Fan, S.J. and Wu, D. (2012) Analysis on the Characteristics of Haze and Clean Weather in Guangzhou and Its Influencing Factors. Chinese Journal of Environmental Scienceh, 32, 1409-1415.

[7] Cheng, Y., Jiang, W.M. and Guo, W.L. (2005) Impact of Urban Agglomeration Development on Regional Air Pollutant Diffusion in Pearl River. Journal of Environmental Science, 25, 700-710.

[8] Wu, D., Tie, X. and Deng, X. (2006) Chemical Characterizations of Solubleaerosols in Southern China. Chemosphere, 64, 749-757. https://doi.org/10.1016/j.chemosphere.2005.11.066

[9] Zhao, M., Xiu, G., Qiao, T., et al. (2016) Characteristics of Haze Pollution Episodes and Analysis of a Typical Winter Haze Process in Shanghai. Aerosol and Air Quality Research, 16, 1625-1637. https://doi.org/10.4209/aaqr.2016.01.0049

[10] Miao, S.G., Wang, X.Y. and Jiang, W.M. (2007) Study on the Impact of Urban Community Planning on Atmospheric Environment. Plateau Weather, 26, 92-97.

Submit or recommend next manuscript to SCIRP and we will provide best service for you:

Accepting pre-submission inquiries through Email, Facebook, LinkedIn, Twitter, etc. A wide selection of journals (inclusive of 9 subjects, more than 200 journals)

Providing 24-hour high-quality service

User-friendly online submission system

Fair and swift peer-review system

Efficient typesetting and proofreading procedure

Display of the result of downloads and visits, as well as the number of cited articles

Maximum dissemination of your research work

Submit your manuscript at: http://papersubmission.scirp.org/

Or contact gep@scirp.org 